\title{
VERNIELING VAN BOOMEN EN PLANTEN DOOR INSECTEN IN KEERKRINGLANDEN.
}

Als men nagaat welke ontzettende verwoestingen van tijd tot tijd in het plantenrijk worden aangericht door zulke schijnbaar onbeduidende schepselen als de gelede dieren, zonder dat de mensch, die er zich op verheft de gansche schepping in hare elementen te kunnen oplossen, de hemellichamen als in de hand te wegen, eenig middel weet te vinden om zulke verwoestingen tegen te gaan, dan voelt men zich geneigd te denken dat de beoefening der natuurwetenschap, althans in dit opzicht weinig praktisch nut oplevert en inderdaad schịnt de Platonische richting die hierin sinds lang gevolgd wordt, weinig geschikt om tot zulke uitkomsten te leiden. Natuuronderzoekers worden onder de bewoners onzer overzeesche bezittingen niet meer gelijk vroeger gevouden; de van Rheedes, de Rumphiussen, de Valentijns, de Merians zijn er uitgestorven en sedert dien tijd is het streven in de wetenschap schier uitsluitend gewijd aan het samenstellen van een volmaakt natuurlijk stelsel, het rangschikken en weder verschikken van planten en dieren, het zoeken naar nieuwe species en derzelver wijze van voortplanting, doch een soms microscopisch insect treedt in een der koloniën onverwachts te voorschijn om een belangrijk middel van het bestaan der gansche bevolking te vernielen en niemand vindt daarvoor in de boeken eenig redmiddel aangewezen, terwijl men in het moederland zelfs na verloop van bijkans veertig jaren niet eens weet welk gedierte de ramp heeft veroorzaakt.

De ondervinding doet mij het Macaulay nazeggen dat hij die zich nimmer in een tropische orkaan heeft bevonden zich van zulk een luchtverschijnsel geen behoorlijk denkbeeld kan vormen en op dezelfden grond meen ik te mogen beweren dat oun de verhalen van sommige verwoestingen door insecten in de keerkringlanden aangericht, te kunnen geloven, men gezien moet hebben hoe een dezer bewerktuigde pesten zich plotseling over 
duizenden van een der meest reusachtige gewassen verspreidt in een land waar het vroeger nooit gezien of gekend was, om ze in het verloop van slechts weinige maanden tot op den laatsten toe te doen sterven.

De periodieke razzias der sprinkhanen - ons reeds uit de Heilige Schrift bekend - zijn snel voorbijgaande en herstellen zich even spoedig, doch er zijn andere soorten bij wier verderfelijken invloed vergeleken die der sprinkhanen als van geen beteekenis te noemen zijn en van wier onverwachte verschijning in even groote of nog grootere getallen het nog moeielijker is verklaring te geven, zoodat het al het voorkomen heeft alsof zij op hoog bevel te voorschijn waren geroepen om de bevolking te tuchtigen - of meer in den geest onzer dagen gesproken alsof zij bij zulke gelegenheden ontkomen waren of ontslagen geraakt van zekeren mededinger naar het oppergezag in de insectenwereld of tegenstander die hen op eene of andere wijze verzwakte en in teugel hield. Juist zoo zwermden achtereenvolgens de Perzische legers over Griekenland, die van Alexander over Azië, de Romeinsche legioenen, de horden onder Attila, de benden der Saracenen over drie werelddeelen en, om de gelijkenis niet te lang te rekken, de Franschen over Europa en de Duitschers over Frankrijk, terwijl bij elk dier gelegenheden de verdrukte volken in verslagenheid vroegen wat de oorzaak was van al dat gewoel even als wij zulks doen naar die van het woelen der gekorven dieren.

In 1518 braken op Hispaniola (Haïti) eensklaps heirlegers mieren (Formica omnivora L. 1) uit den grond met het blijkbare oogmerk om de eerste Europesche bezitters van het eiland te verdrijven door middel van alles wat eetbaar was te verslinden en werkelijk zouden zij in dat opzet geslaagd zijn, ware St. Saturnin niet nog in tijds op aanzoek der bevolking tusschen beide gekomen om het te verhoeden, ${ }^{2}$ ofschoon hij niet kon verhinderen dat de stad Sevilla Nueva in een ander deel van het eiland door hetzelfde middel onbewoonbaar werd gemakt.

Deze overlevering zou, wat de opstand der mieren betreft, zeer waarschijnlijk in twijfel worden getrokken, zoo niet in $\mathbf{1 7 6 0}$

1 Myrmica omnivora Latr. Sir Robert Schomburgk geeft in zijn a History of Barbados» de kenteekenen er van op volgens Dr. Poh! en v. Kollar. Zij komt echter bij sommige auteurs voor onder den naam $F$. saccharivora, terwijl Sir Robert daarmede een andere soort schijnt te bedoelen.

2 Zie Bijlage I. 
en daarop volgende 20 jaren dezelfde mierensoort in onderscheidene veldtochten zulk een reeks van schitterende overwinningen op zijn hooger bewerktuigde overheerschers in andere eilanden behaald had dat dezen niet wisten wat te doen of waar zich te bergen om aan hunne vervolging te ontkomen, sedert welken tijjd niemand er aan denkt de roemrijke daden van hun voorgeslacht in Hispaniola te betwisten. Men oordeele slechts uit de volgende korte trekken der geschiedenis van West-Indië over het bedoelde tijdvak.

In genoemd jaar richtten zij op Barbados, al waar zij zoo men beweerde, in tuinaarde waren aangebracht, zoodanige verwoestingen aan, zoowel in het dieren-als in het plantenrijk, dat de bevolking er ernstig aan dacht te capituleren en hen het eiland in eigendom aftestaan waartoe het plaatselijk gouvernement in beraadslaging trad over de noodige maatregelen bij de overgave in acht te nemen ${ }^{1}$. In 1763 vertoonden zij zich even schrikbarend op Martinique, van waar zij in 1770 werden overgevoerd naar Grenada, in welk laatstgenoemd eiland zij achtereenvolgens een aantal suikerplantaadjes onbruikbaar maakten, zelfs het vee, zieke menschen en kleine kinderen aanrandende. De krachtdadigste middelen waren onvermogend hun aantal te verminderen veelmin hen uitteroeien. Bijtende sublimaat had de uitwerking hen als verwoed op elkander te doen aanvallen en waar men hen zocht te verbranden wierpen zij zich in zulk eene menigte in de vlammen dat het vuur er door uitdoofde. Het gouvernement van Martinique loofde een prijs uiț van een millioen francs; dat van Grenada bood 20,000 pd. st. voor een middel om hen te verdelgen, doch vruchteloos en het was alleen de orkaan van 1780 die deze bezoeking kon doen verdwijnen.

In 1814 vertoonden zij zich op Barbados plotseling voor de tweede maal in ontzettende mate, doch verminderden ook weer even spoedig, sedert welken tijd zij daar, hoewel in geringen getale, aanwezig zijn gebleven. Over de oorzaak van dit laatste verschijnsel laten de auteurs zich niet uit, doch niets is natuurlijker dan de gevolgtrekking, dat deze gevreesde mieren eindelijk een tegenstander hadden gevonden om hunne overmatige aangroei in getalsterkte tegen te gaan, en aldus het evenwicht dat zij vroeger verstoorden te herstellen.

De groothoofdige mier (F. Cephalotes Fab.) de Cushi der

1 History of Barbados als boven. 
negers in Guyana 1 en onder die van Curaçao als Hane-hane bekend, is wellicht niet minder geducht dan de vorige en zoo hare verwoestingen ook al binnen engere grenzen beperkt zijn gebleven, is zulks alleen daaraan toe te schrijven dat ze zich nog nimmer in gelijk aantal heeft vertoond. In Guiana bepalen zij zich meestal tot het vernielen van aardvruchten, z. a. zoete bataten, cassave, yams en moeskruiden, waarvan zij de stengels en bladen afknabbelen, terwijl zij van Turksche tarwe (Zea maize L.) waar die te veld staat de aren afbijten en die medevoeren. Bij zulke gelegenheden vertonen zij zich ontzachwekkend genoeg om menschen en dieren voor zich te doen wijken. In millioenentallen marcheren zij dicht aaneengesloten voorwaarts onder de leiding van hoofden en guides, zonder zijdelings aftewijken, onverschillig wat hun in den weg komt, woningen en provisiègronden binnendringende terwijl deze door de eigenaars worden ontruimd. Op de West-Indische eilanden echter hebben zij zich, meen ik, nergens in die mate vertoond en ook nimmer belangrijke schade angericht, hetwelk redelijker wijze alleen kan wordcn toegeschreven aan het bestaan van een of ander vijandig ras dat hunne vermenigvuldiging daar beperkt.

Is het ons nu niet wel doenlijk de oorzaak natesporen die de in den grond levende mieren zoo eensklaps in de bovenvermelde mate doet vermenigvuldigen, welke verontschuldiging hebben wij dan voor onze onwetendheid als het de in de vrije natuur levende, parende en eijerleggende vlinders betreft. Hoor wat $\mathrm{Du}$ Tertre ons verhaald: "Apres cet Ouragan 2 il demeure une certaine infection dans l'air, qui engendre une telle quantité de chenilles, que la terre en estoit toute couverte; elles estoient si prodigieusement longues et grosses, que jamais on n'en a veu de pareilles dans l'Europe; elles broutoient les habitations en si peu de temps et d'une si deplorable manière, qu'on eut crû que le feu y avoit passé " 3 . Hier worden zij uitgebroeid door de lucht, doch in zijn Histoire Naturelle van het eiland wordt van Papillons of van Chenilles, waarvan er onderscheidene op het eiland aanwezig zijn, geen het minste gewag gemaakt.

Niet meer licht ontvangen wij van Sir Robert Schomburgk die een dergelijk geval verhaalt als in 1846 te hebben plaats

1 History of Barbados. Zie ook Dalton's History of British Guyana, vol. 11, p. 296.

2 Die van 1656 te Guadeloupe.

3 Histoire général des Antilles. T, 1, p. 497. 
gehad nabij Colleton op Barbados; waar een veld zoete bataten (Batatas edulis Chois.) van tien acres (5 hectare ongev.) in een enkelen nacht van zijn loof werd beroofd door een zwerm rupsen. Zoodra dezen het veld hadden schoon geveegd trokken zij in gesloten gelederen dwars over den grooteu weg naar een ander veld, in welke flank marsch duizenden er van door de hoeven van paarden en wielen van rijtuigen werden fijn gekneed. Een zware stortregen die juist toen inviel, spoelde geheele hoopen er van in de greppels langs den weg, waar Schomburgk ze zag liggen. Voor de oorzaak van hun plotselijk ontstaan waagt deze begaafde reiziger zich echter zelfs niet aan een gissing en is het al veel dat wij iets te weten komen van het geslacht der Lepidoptera waartoe zij behoorden, hetwelk hij zegt waarschijnlijk de Chœrocampa te zijn geweest.

Op het suikerriet schijnen onderscheidene der gelede dieren ongemeen verlekkerd te zijn, die daarbij het vermogen bezitten om de geheele aanplant er van, zelfs over uitgebreide landstreken, jaren achtereen te doen verloren gaan, echter altijd, voor zooveel ik heb kunnen te weten komen, alleen in de landen waar het niet inheemsch maar van elders is overgeplant. In West-Indië wordt geen van deze door de planters meer gevreesd dan de Boorworm, de Yellow blast der Engelschen, zijnde de larve of rups van een Mot, beschreven onder de naam van Diatrea Sacchari van de orde der schubvleugeligen (Lepidoptera) 1. Deze op het oog nietige worm doorboort het riet aan de leden, waar de Mot hare eijeren onder de daar aangehechte bladeren heeft gelegd, door welke opening de lucht binnen dringt en het sap verzuurt, zoodat het met sap van onbeschadigd riet vermengd zulks eveneens bederft.

Het was tegen de Boorworm dat op St. Eustatius in 1789 door den Gouverneur a. i. Joannes Runnels, een vast- en bedendag werd uitgeschreven. Dat het insect later verdwenen is en het zich daarna - altans tot het jaar 1847 - op dat eiland niet meer vertoond heeft is zeker, doch of zijne verdwijning ongemerkt heeft plaats gehad dan wel of daartoe eenige zichțbare agent is gebezigd, wordt niet vermeld. Het zal dus hoop ik bestaanbaar worden geacht met gevoelens van het diepst ontzag voor het opperwezen als ik aanneem dat het laatste werkelijk het geval is geweest.

1 History of Barbados als boven. 
In 1854 werd doer het Gouvernement van Mauritius een belooning van 50,000 francs uitgeloofd voor een middel tegen de Boorworm die destijds op dat eiland het suikerriet verwoestte 1 . Voor het oogmerk van eeu krachtvoller plantsoen te kweeken had men daar riet-toppen uit Britsch-Indië doen aanvoeren, doch men had tevens het Trojaansche paard ingehaald, want van stonden af aan verspreidde zich de Boorworm, die tegelijk met de toppen was overgekomen, onbedwongen door dien natuurlijken vijand welke op het vaste land zijne vermenigvuldiging zoo zeer had tekeergegaan dat men van zijn bestaan niet eens kennis droeg.

Als plagen van het suikerriet vindt men bij Sir Robert Schomburgk nog vermeld de door de negers genoemde grou-grou worm, de larve van Calandra palmarum Fabr. ${ }^{2}$ alsmede de Groote Borer (Calandra Saccharis Guild.), terwijl na de orkaan van 1831 zich op dat gewas bovendien een "Rietvlieg" van de orde Hemiptera en in latere jaren nog twee andere hoogst schadelijke insecten, waarschijnlijk behoorende tot de Aphisida en Coccida, hebben vertoond, als om vereenigd met de emancipatie der negers, den geheelen ondergang van de suiker-cultuur in W. I. en daardoor die van de daar gevestigde Europesche volksplantingen te voltomien.

De kokosboom (cocos nucifera L.) ofschoon in West-Indië zeer goed kunnende aarden, voor zooveel het klimaat en den bodem betreft, is daar echter sedert de laatste veertig jaren zoozeer ten prooi aan insecten dat, tenzij eenig middel gevonden wordt om dezen te verdrijven, men naar het zich laat aanzien weinig hoop heeft die schoone en nuttige palmen daar te behouden. Op Barbados, waar in de reeds boven aangehaalde orkaan van 183I meest alle kokosboomen verwoest waren, werd dat verlies weldra door een nieuw plantsoen hersteld, doch nauwelijks was dit begonnen vruchten af te werpen toen een tot dien tijd daar onbekend insect - in de "Gardiners Chronicle" van 2 Me1 1846 Aleyrodes Cocoïs genoend - zich over de blad-

1 De Gids in het plantenrijk onder redactie van Becker Scaiongue en Michell. 1e jaarg. 1871.

2 Deze legt zijne eijeren echter bij voorkeur in den stam van palmboomen, vournamelijk in die van de Acrocomia fusiformis. Hij of $\mathrm{B}^{\mathrm{s}}$; volgens Dalton worden zijne larven gevonden in het hart van de koolpalm hetwelk in West-Indie de naam is van Oreodoxa oleracea. Mart., H. of B. G. 
kroonen verspreidde en deze vorstelijke gewassen in korten tijd tot op den laatsten toe deed omkomen '

Deze gebeurtenis is beschreven door den beroemden geschiedschrijver van dat eiland, wiens naam reeds zoo dikwijls in deze bladen is aangehaald en hij voegt er ten slotte bij dat het insect toen reeds bezig was zijn vernielingswerk voorttezetten over Antigua, Nevis, St. Christophel en andere eilanden, waarin Martinique als in dezelfde lịnn gelegen begrepen is. Van dit laatstgenoemde werd het in 1837 met Z. M. Brik de Echo, op welken bodem ik destijds als Luitenant diende, waarschịnlijjk ter gelegenheid van het overbrengen van een aantal met aarde gevulde bakken waarin Nopal-planten stonden die met het Cochenille insect bevolkt waren, naar Curaçao overgebracht, teu gevolge waarvan ook op dat eiland de geheele aanplant van de genoemde palmsoort, ongeveer 20.000 in getal, nog voor het einde van het jaar 1839 vernietigd werd.

Ofschoon nu wat de overbrenging van het insect uit Martinique betreft, zulks nimmer officieel geconstateerd is, zoo valt het toch niet te betwisten dat genoemde oorlogsbrik in Maart van het opgenoemde jaar te St. Pierre Martiuique Nopal- of cactusplanten heeft ingenomen, dat volgens later in de Curaçaosche Courant van 13 Julij 1839 vermelde berichten uit Martinique de kokosboomen op dat eiland door een insect zijn vernield geworden en eindelijk dat de door Sir Robert Schomburgk geleverde beschrijving van de wijze waarop de vernieling van de kokosboomen op Barbados zich heeft toegedragen, woord voor woord overeenkomt met die welke is waargenomen te Curaçao ${ }^{2}$. (Zie Bijlage II.)

1 Nader leest men dienaangaande dat de correspondent van het opgemelde nuttige tijdschrift aan de onderzijde van het kokosblad twee verschillende insecten ontdekte, een waarvan het bovengenoemde, het andere een coccus (schildluis) was. History of Barbados, p. 649, 650.

2 Laat niemand zich verwonderen dat zelfs nog kort geleden de vernieling van de kokosboomen op Curaçao door «een geleerde" is toegeschreven aan de rups van een avondvlinder. Zulke vlinders op $60-80$ voet boven den grond te laten zweven om hunne eijeren te leggen in de kroon van kokosboomen, is reeds ongeloollijk genoeg, doch dat zij de bedoeide boomen op Curaçao zouden hebben vernield is even onwaar als dat zooals op de hoogere Burgerscholen in Nederland onderwezen wordt de dalgronden op Curaçao voordeelige mä̈s en SUIKEROOGsTEN opleveren, en St. Eustatius veel katoen, tabak, indigo en kofie produceert.

NB. Een voordeelige maïs-oogst is op Curaçao een even groote zeldzaamheid als een plant suikerriet, en wat st. Eustatius betreft, het 
Het hier bedoelde insect of wel larve - hetzị dan van de genoemde Aleyrodes, hetzij van een schildluis, gelijk het in de Curaçaosche Courant van die dagen genoemd werd, - heb ik van September 1838 tot November 1839 op de plantaadje klein St. Joris in de oostdivisie van het eiland, schier dagelijks onder de oogen gehad terwijl ik al het mogelijke in het werk stelde om het van de boomen te verdrijven, op grond waarvan ik kan verklaren dat het zich niet anders vertoonde dan als platie cirkelvormige vliesjes van één millimeter in doorsnede welke bij milliarden onbeweeglijk, als zaten zij vastgekleefd, de frondes en vruchtmakende deelen overdekten ${ }^{1}$.

Omstreeks denzelfden tijd dat aldus de kokosboomen op de W. I. eilanden voor een lange reeks van jaren werden uitgeroeid, - eerst sedert kort begint men op Curaçao hoop te voeden dat een nieuw plantsoen tot vollen wasdom zal komen werd dat gewas in de landstreek van Guiana geteisterd, even als het nog steeds gedaan wordt, door een kever die volgens de berichten van ooggetuigen, eigenaars van plantages, aan den voet der boomen in den grond gravende - alleen in zandgrond wil hem zulks niet gelukken - zich, vergezeld van het wijfje, een weg baant naar het ondervlak van den wortelstok, in het centrum waarvan, als zijnde het zachtste deel, hij een gat boort om er in te komen en eenmaal daar binnen gedrongen, met zijn gezellin door het losse weefsel in het hart van den stam, den top weet te bereiken, waar beiden, vereenigd met de later uitkomende larven, de zachte en malsche palmiet wegknagen, zoodat de boom sterft nog vóór dat de frondes teekens geven van zijn veegen toestand.

De hier vermelde wijze van werken dezer kevers werd voor het eerst bekend gemaakt door den heer W. Russell, planter in Demerary, die hen lang en zorgvuldig heeft nagespoord en van zijne bevinding het verslag heeft voorgedragen in een der maandelijksche vergaderingen van de Royal Agricultural and Commercial Society te dier plaatse, waarna het is overgenomen in "The Royal Gazette, Georgetown British Guyana" van 4

eenigste wat het ooit geproduceerd heeft is een weinig suiker en yams, doch sedert de emancipatie van de slaven, niets dan het laatste artikel voor eigen verbruik.

1 De larve van Aleyrodes Chelidonii, zoodanig als die in de boeken is afgebeeld, o. a. in Snellen van Vollenhoven's «De Irsecten», bl.133 geeft een vrij goede voorstelling van bovenbedoelde. 
Maart 1876, terwijl het in elk opzicht bevestigd wordt door de reeds vroeger gedane waarnemingen van een geacht vriend, den heer A. D. van der Gon Netscher, voormalig eigenaar van de plantage "Klein Poederooye" in bedoelde landstreek gelegen, saamgevat in een bericht mij welwillend in handen gegeven. Laatstgenoemde heer is tevens bezitter van een paar der bedoelde kevers, ongetwijfeld $\delta$ en $\$$, door een zijner koelies in den vroegen morgen - de eenigste tijd dat zij te vangen zijn op heeter daad betrapt en gevangen genomen, terwijl zij gezamenlijk bezig waren hun loopgraaf naar een kokosboom te openen. Beiden zijn mij gebleken volkomen te beantwoorden, het mannetje aan de opgegeven kenteekenen van Scaraboers Aloë, het wijfje aan die van $S$. Aloëus, in de "Catalogus Systematicus Coleopterorum" van Dr. Voet en daar als uit Suriname af komstig opgegeven.

Over de mate van verwoesting door deze soort kevers op genoemde plantage aangericht laat de heer $\mathrm{N}$. zich aldus uit: "Met het oog op het belangrijke en zekere voordeel aan het bezit van kokosboomen verbonden, deed ik reeds in 1842 eenige honderden jonge kokosboomen op daarvoor best geschikte plaatsen uitplanten. Bijna allen kwamen weelderig op en van jaar tot jaar daarmede voortgaande had ik niettegenstaande het telkens wegsterven der 4 en 5 jaar oude boomen in 1857 reeds meer dan 20.000 boomen geplant, waarvan geen duizend leefden, en ben ik tot mijn groote spijt overtuigd geworden dat de kevers de verwoesters waren, waarvan ik er u twee - men zeide mij, het maunetje en het wijfje - tot kennisneming en onderzoek aanbood."

Ik moet hier evenwel opmerken dat de heer Russell de door hem in de vergadering vertoonde kever door zijn vriend Dr. Whitlock Passalus tridens laat noemen, hetwelk zou doen denken dat de Scrarabœus niet alleen staat als vernieler der kokosboomen in Guiana, doch behalve dat genoemde Passalus, die ik door de vriendelijke vergunning van den heer Ritsema in het museum te Leiden gezien heb, geenszins gevormd schijnt om tot in kokosnoten gaten te maken alsof zij - gelijk de verslaggever het uitdrukt, - met een avegaar geboord zijn, komen ook de door den heer Russell opgegeven kenteekenen overeen alleen met de Scarabœus Aloë, hoewel het mogelijk is dat de Passalus dezen in de door hem gemaakte opening achteraan sluipt. - In de door Dr. Dalton in zijne "History 
of British Guijana opgenoemde acht soorten van het geslacht Passalus, als in die landstreek voorkomende, wordt P. tridens niet gevonden.

Overigens handelt het zeer wijdloopig verslag van den heer R. over de Aleijrodes Cocoïs welke zich, zoo men daar leest, drie jaren te voren almede op de kokosboomen in Guiana is beginnen te vertoonen en daar meer dan eenige keversoort die edele palmen met totale vernietiging bedreigt.

Bovenstaande bijzonderheden, schier uitsluitend de W. I. kolonien betreffende, meen ik niet geheel van belang ontbloot te zijn ook voor de Nederlandsch-Indische bezittingen, waar aanplantingen van onschatbare waarde z. a. die van den koffieboom, om niet van andere te reppen, aan dezelfde gevaren bloot staan als die welke hier zijn aangebaald. Met elken dag kan er, vooral bij gelegenheid van het overbrengen van vreemde gewassen naar de Botanische tuin te Buitenzorg, een insect worden overgebracht, hetwelk z. a. in onderscheidene gevallen elders gebleken is, onberekenbare schade kan aanrichten en eenmaal over het land verspreid niet meer uitteroeien is of eerst na jaren tijdverloop verdwijnt. Om zulke gevaren te ontwijken wordt een kennis vereischt die alleen door onderzoek in de vrije natuur - niet in de studeerkamer - te verkrijgen is, namelijk die van de soorten der gekorven dieren welke van nature bestemd zijn elkanders overmatige vermenigvuldiging tegen te werken. Toen de Aleyrodes Cocoïs als in een oogwenk op. Barbados vermenigvuldigde gelijk het zand der zee, zeide een uitstekend entomoloog: "it is remarkable that no parasitic insect should have appeared to check its increase, but this may arise from the disease having been imparted without its usual antidote!" Hetzelfde past voor de overbrenging en verbreiding van zooveel anderen, en ziedaar de oorzaak van het euvel zoowel als het geneesmiddel. Ware ons een parasiet of antagonist van elk der coleoptera bekend, wij zouden in Nederland niet behoeven te sidderen voor de komst van de Colorado-kever. Op - St. Eustatius zag ik zulk een tegen de vliezige wants, meer bekend onder den naam van weegluis, en de geredelijkheid waarmede men daar als het tepas komt ledekanten en bedden binuen weinige uren op de meest radikale wijze van dat ongedierte zuivert, eeniglijk door er zekere soort kleine zwarte brandmieren in aantebrengen die in een enkelen nacht tot zelfs de eijeren er van vernietigen, zou tegenwoordig in Frankrijk menig
Downloaded Prom Brill.come4/26/2023 $02: 05: 34 \mathrm{PM}$ 
"Vigneron" den mond doen wateren bij de gedachte aan een dergelijk middel tegen de Phylloxera die zijn wijngaard verwoest. De europesche Aleyrodes wordt door de Scijmnus omgebracht; in O. I. heeft de Termes vermogende vijanden onder de mieren enz. Zulke voorbeelden leerén ons dat men op soortgelijke wijze ook andere insecten-plagen zal kunnen bestrijden en wat mij betreft: "assuming the well being of-the human race to be the end of all knowledge," 1 ken ik geen nuttiger toepassing van de kennis der insecten. Hij die er in slaagt in voorkomende gevallen zulk middel te verschaffen zal er roem en voordeel mede behalen, de menschheid een onschatbaren dienst bewijzen en entomologie verheffeu tot de eerste en gewichtigste tak der natuurwetenschap.

A. H. Bisschop Grevelink.

's Gravenhage, Februari 1877.

1 Lord Bacon, De Augmentis Scientiarum, in Macaulay's Essays. 


\section{B IJ I, A G E N.}

I. Verhaal bij Herrera (vertaling van de la Costa) Tom. 2. Livre III p. 222-6.

"Le soin que prenoient les Peres Hieronimites ne s'étendoit pas seulement sur les Indiens; mais ils faisoient ce qu'ils pounoient pour le persuader aussi aux Castillans, afin qu'ils s'adonnassent au labourage, parce que cette terre est fort fertile. Et comme en l'an 1506, vn habitant de la Vega, appelié Aguilon, y transporta de Canarie des cannes de sucre, et les planta, elles creurent aussi de telle façon, qu'un nommé Vellosa, habitant de St. Dominique, chirurgien, natif de Verlanga, s'adonna à faire pulluler ce plan de telle sorte que par le moyen de certains instrumens il en tira du sucre, et en fit enfin vn Trapiche 1. De sorte que les Peres Hieronimites voyant que de sa nature cette terre estoit fort fertile, et reconnoissant qu'elle estoit extrémement propre pour profiter, ils ordonnerent que l'on prétast cinq cens poids d'or a chaque habitant pour faire des engins a sucre, et par ce commencement il s'entrouua en peu de temps quarante à eau et à cheual. Il faut noter qu'anciennement il n'y auoit point de sucre que dans Valence, et en suite dans Grenade, d'ou il passa en Canarie, et de la aux Indes, ce qui donna sujet d'y faire passer des Negres, pour estre gens de grande fatigue. Les Negres esprouverent aussi dans l'isle Espagnolle, que l'on eut opinion que si l'on ne pendoit un Negre, il ne mourroit iamais, parce que iamais l'on n'eu à veû aucun finir par maladie. Ainsi donc les Negres trouverent dans l'Espagnolle leur propre terre, comme les oranges, qui leur est plus naturelle que leur Guinée.

Les castillans commencant donc à iouir du fruit de leurs trauaux, et a accomplir l'esperance du gain qu'ils en pretendoient tirer, Dieu enuoya sur l'isle Espagnolle et particulierement sur l'isle de Saint Jean, vne playe que s'il eust falu qu'elle eust duré, elle eust depeuplé l'Isle entierement: c’estoit

1 Trapiche est le lieu et l'engin avec quoy l'on fait le sucre. 